BOOKS

\title{
A frank expression of life with a disability
}

7 Wheelchairs: A Life Beyond Polio

Gary Presley

University of lowa Press; 2008.

226 pp $\$ 25.95$

$\mathrm{P}$ atient accounts have the potential to be weighted less than those of their more professional caregivers in the narrative medicine explosion and indeed there seem to be fewer published. Recently, we've seen a proliferation of online blogs, which are often little more than a bin of comment clouds. So it is refreshing to read Gary Presley's memoir, 7 Wheelchairs: A Life Beyond Polio.

Presley developed polio at the age of 17 after an inoculation went wrong and has been in a wheelchair for 50 years. The book can be summed up as a coming to terms with the many feelings his disability wrought: anger, frustration, self-pity, and ultimately transcendence. Initially, the disability violently orients Presley, steals the very air away from him and thrusts him into an iron lung, but through persistence and acquired courage the author doesn't allow the disability to become his identity, he adapts to it. Thus the book becomes less about disability and brokenness and more about thriving.

If all of this sounds like the traditional narrative arc of a book about survivorship, that's because it is - the initial shock followed by despair and then acceptance - but what's remarkable a about Presley is his excoriating honesty. He admits he was, initially, a tough patient to love: an unappealing and callow adolescent, possessed by selfinterest, a perpetual whiner to hospital staff and family members. His anger was transposed onto those who cared

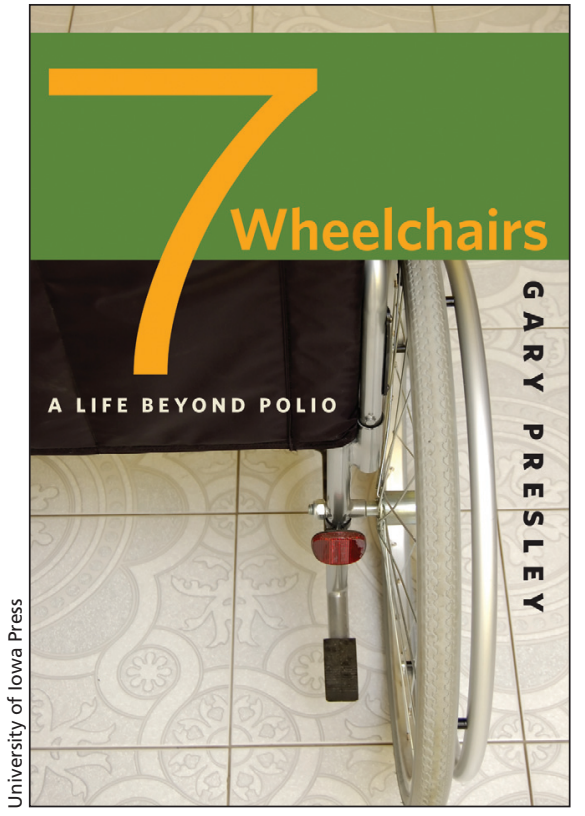

for him, sometimes described as inept, sometimes uncaring and mechanical.

Presley spares no one, including medical practitioners, but most of all, himself. The trick he pulls off so well is that he allows us to feel his emotions as he was feeling them, from the cruelly disabledin-the-moment to the summative memoirist and adult who faces his unpleasant self with wisdom and empathy.

It would be patronizing to suggest that the adversity Presley faced built character - I can see the author bristling as he reads this - but it is undeniable that this is a book written by someone who is self-aware. This might be attributable to growing older, but it is hard not to conclude that there was also a strange benefit to Presley's condition, for the reader sees Presley grow as the book progresses. Perhaps Presley would have become an exceptional person outside of disability. It's impossible to know.
The main strength of this book is on the plane of experience, not at the level of the sentence. Presley is not a prose stylist. A better writer might have wrung more out of his pain, might have made us feel the emotions that Presley only names. In addition, the cast of characters are merely drawn, never dramatized - there is very little dialogue, for example - and so we are unable to derive our own conclusions about them. However, when Presley actually lets his characters interact, the results are quite affecting. In one scene, the teenage Presley argues with his father bitterly about whether his disability is "God's will." The pathos of the narrative sharpens into genuine sadness and the irreconcilability of father and son is evident, thus this snippet of dialogue allows insight into this relationship.

Another success comes in the very real day-to-day fear of suffocation Presley suffers as a result of diaphragmatic paralysis, traceable to an experience early on in his disability when he was mistakenly disconnected from a respirator. This fear is ever-present and palpable, and lends what Presley writes an incantatory quality.

Doctors learn best from patients and the best learning experiences are anecdotes. Presley's story is a metaanecdote: He has something to say to the doctor who might be frustrated with the unreachable adolescent or to the patient with learned helplessness. He has something to say about disability in general, about how disability plays out in hospitals and in the home.

\section{Shane Neilson MD}

Author and poet

Guelph, Ont. 